\title{
A rare case of fallopian tube lymphangioma
}

\section{Srikala Doddareddy*, Shravya Manohar, Sumana Manohar}

Department of Obstetrics and Gynecology, Apollo Women's Hospital, Chennai, Tamil Nadu, India

Received: 23 September 2020

Accepted: 31 October 2020

\section{*Correspondence:}

Dr. Srikala Doddareddy,

E-mail: chand4191@gmail.com

Copyright: (C) the author(s), publisher and licensee Medip Academy. This is an open-access article distributed under the terms of the Creative Commons Attribution Non-Commercial License, which permits unrestricted non-commercial use, distribution, and reproduction in any medium, provided the original work is properly cited.

\section{ABSTRACT}

Lymphangioma of the fallopian tube is a very rare lesion, usually present as benign lesions of the lymphatic system. They are generally diagnosed incidentally, may be asymptomatic or present as a palpable abdominal mass. Lymphangiomas are usually seen in the head and neck region, intra-abdominal localisation is rare. A very limited number of cases of fallopian tube lymphangiomas have been reported. We present an extremely rare case of unilateral fallopian tube lymphangioma (right side) in a 32 year old parous lady who was presented to us with right lower abdominal pain. Clinically no significant findings were noted. CECT abdomen reported as a probable endometriotic cyst. On laparoscopy she was found to have a cystic lesion arising from the right fallopian tube. Patient underwent right salphingo-oophorectomy and histopathology reported as lymphangioma of the fallopian tube.

Keywords: Pain abdomen, Adnexal mass, Lymphangioma

\section{INTRODUCTION}

Lymphangiomas are benign lesions characterised by proliferation of lymphatic vessels. Lymphangioma usually occur during the first 2 years of life. ${ }^{1}$ Intrabdomianl lymphangiomas have been reported in the gastointestinal tract, mesentery, liver, pancreas, gall bladder, spleen and adrenal gland. ${ }^{2}$ There are reported cases in the pelvic area, rarely in the ovaries, fallopian tube and inguinal region. ${ }^{3-8}$ It is seen in the elderly and is often asymptomatic and diagnosed incidentally. They are brought to the attention of the obstetrician only if they reach a larger size or cause a complication. We present a very rare case of lymphangioma of the right fallopian tube in a 32-year-old parous lady with a tubal mass on laparoscopy along with CECT whole abdomen and histopathological examination.

\section{CASE REPORT}

Current case presents a 32-year-old parous lady with lymphangioma of the fallopian tube. She was admitted to the department of obstetrics and gynecology, for right lower abdominal pain. No other significant symptoms in the history and findings on physical examination.

With clinical suspicion of right adnexal pathology, transvaginal ultrasound scan evaluation was done, which showed dilated pelvic vasculature. For further evaluation, CECT abdomen was done and showed a probable differential diagnosis of endometriotic cyst, haemorrhagic cyst, leaking ectopic. Ectopic pregnancy ruled out by insignificant beta $\mathrm{HCG}$ report $(<5.0 \mathrm{mIU} / \mathrm{ml})$. In view of right lower abdominal pain and suspicious endometriotic cyst on CECT abdomen, laparoscopy was performed under general anaesthesia after informed consent and pre anaesthesia clearance.

\section{Intra operative findings}

Adnexal mass of size $5 \times 4 \mathrm{~cm}$ was arising from the anterior aspect of right mesosalphinx extending up to the round ligament (right side). Left fallopian tube and both ovaries and uterus were found to be normal. 


\section{Treatment}

Patient underwent right salphingo-oophorectomy and the specimen was sent for histopathological examination, which revealed lymphangioma arising from the right fallopian tube.



Figure 1: Transvaginal scan of right adnexal mass.

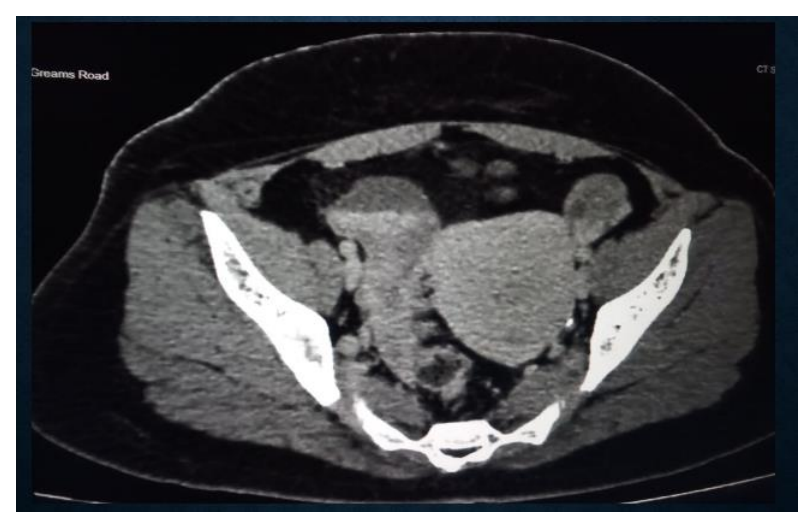

Figure 2: CECT Abdomen showing right adnexal mass.

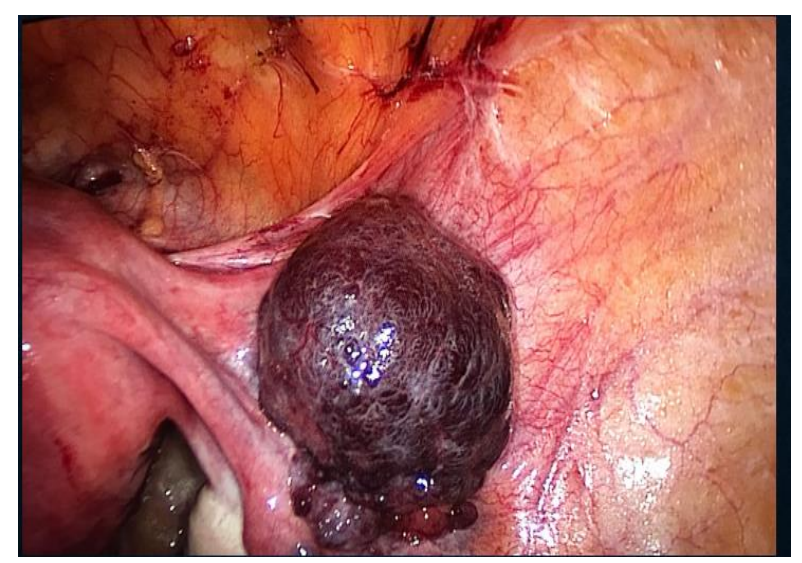

Figure 3: Intra-operative picture of right adnexal mass.

\section{Outcome and follow-up}

Post-operative period was uneventful. In a follow-up period of 2 years, no recurrence of disease by clinical and radiological examination. Informed consent was obtained from the patient prior inclusion of details in current case report.

\section{DISCUSSION}

Most of the retroperitoneal lymphangiomas are asymptomatic. Benign soft tissue tumours may involve the fallopian tube. Leiomyomas are most common. Other benign tumours are lymphangioma, lipoma, schwanoma, angiomyolipoma and chondroma. ${ }^{9}$ Lymphangioma is a rare benign tumour of lymphatic tissue and thought to result from developmental failure of the lymphatic tissue. ${ }^{9}$ Lymphangiomas are malformations arising from sequestered lymphatic channels or acquired lesions due to obstruction caused by fibrosis of lymphatic channels. ${ }^{10}$

Lymphangiomas tend to occur in the first 2 years of life. They can occur at any age and most are asymptomatic. The most common presenting clinical symptoms are related to the size of the lesion. Size of the lesion is important than its location to the symptomatology development.

Lymphangiomas are usually asymptomatic and diagnosed incidentally during radiological investigation (ultrasound/CECT abdomen) or during surgery. Radiological methods provide important information for determining the diagnosis, nature of lesion and the relationship between neighbouring organs. Definitive diagnosis made with histopathological examination. As spontaneous regression of these tumours are rare and there is risk of recurrence. Surgical treatment is necessary and complete excision of the tumour is the preferred method.

Patient was found to have a large cystic lesion arising from the fallopian tube on CECT whole abdomen. Total excision of the lesion was done (right salphingooophorectomy). Final diagnosis was made by histopathological examination. There are reports that these tumours can behave in malignant manner and these patients should be followed up for 2 years to exclude recurrence. ${ }^{11}$

\section{CONCLUSION}

Lymphangioma of fallopian tube is extremely rare, which is to be kept in the differential diagnosis when patient presents with lower abdominal pain.

\section{Funding: No funding sources Conflict of interest: None declared Ethical approval: Not required}




\section{REFERENCES}

1. Bhavsar T, Saeed-Vafa D, Harbison S, Inniss S. Retroperitoneal cystic lymphangioma in an adult: A case report and review of the literature. World $\mathbf{J}$ Gastrointest Pathophysiol. 2010;1(5):171-6.

2. Koenig TR, Loyer EM, Whitman GJ, Raymond AK, Charnsangavej C. Cystic lymphangioma of the pancreas. AJR Am J Roentgenol. 2001;177(5):1090.

3. Akyildiz EU, Peker D, Ilvan S, Calay Z, Cetinaslan I, Oruc N. Lymphangioma of the ovary: a case report and review of the literature. J Buon. 2006;11(1):91-3.

4. Evans A, Lytwyn A, Urbach G, Chapman W. Bilateral lymphangiomas of the ovary: an immunohistochemical characterization and review of the literature. Int J Gynecol Pathol. 1999;18(1):8790.

5. Singer T, Filmar G, Jormark S, Seckin T, Divon M. Rare case of ovarian cystic lymphangioma. J Minim Invasive Gynecol. 2010;17(1):97-9.

6. Aristizabal SA, Galindo JH, Davis JR, Boone ML. Lymphangiomas involving the ovary. Report of a case and review of the literature. Lymphology. 1977;10(4):219-23.
7. Nigam S, Sharma D, Manaktala U, Chaturvedi KU. Lymphangioma of the fallopian tube-a case report. Indian J Pathol Microbiol. 2004;47(2):225-6.

8. Goel R, Agarwal A, Lomanto D. Large lymphangioma presenting like irreducible inguinal hernia: a rare presentation and literature review. Ann Acad Med Singapore. 2011;40(11):518-9.

9. Sanes S, Warner R. Primary lymphangioma of the fallopian tube. Am J Obstet Gynecol. 1939;37:31621.

10. Evans A, Lytwyn A, Urbach G, Chapman W. Bilateral lymphangiomas of the ovary: an immunohistochemical characterization and review of the literature. Int J Gynecol Pathol. 1999;18:87-90.

11. Khanna S, Mehrotra ML, Basumallick MK. Lymphangioma cavernosum of the ovary. Int Surg. 1978;63:104-5.

Cite this article as: Doddareddy S, Manohar S, Manohar S. A rare case of fallopian tube lymphangioma. Int J Reprod Contracept Obstet Gynecol 2020;9:5169-71. 